Silvio Luiz de Sousa

Rollemberg

silviorollemberg@gmail.com Universidade Federal do Ceará (UFC)

Amanda Nascimento de Barros iD

amandanbarros11@gmail.com Universidade Federal do Ceará (UFC)

João Pedro Machado de Lima

jpedro_mdl@hotmail.com Universidade Federal do

Ceará (UFC)

\section{Avaliação da contaminação, sobrevivência e remoção do coronavírus em sistemas de tratamento de esgoto sanitário}

\section{Evaluation of contamination, survival and removal of coronavírus in wastewater treatment systems}

\section{Evaluación de la contaminación, supervivencia y remoción del coronavirus en sistemas de tratamiento de alcantarillado sanitario}

\section{Évaluation de la contamination, de la survie et de l'élimination du coronavirus dans les systèmes de traitement des eaux usées}

\section{Resumo}

O mundo vem sofrendo uma das mais fortes pandemias da história, causada pelo vírus SARS-CoV-2. Até agora, há relatos de aproximadamente nove milhões e sete mil de infectados no mundo. Embora não haja relato conclusivo sobre a transmissão fecal-oral do novo coronavírus entre pessoas, acredita-se que esse tipo de transmissão seja possível, uma vez que o SARS-CoV-2 já foi detectado em efluentes domésticos e em fezes de pacientes. Este artigo consiste em uma revisão de literatura avaliando a sobrevivência dos vírus da família Coronaviridae através do esgoto, seja pela presença no efluente (corrente líquida), seja pela presença no lodo de estação de tratamento, que poderão causar contaminações pelo manejo inadequado dos resíduos produzidos no sistema de tratamento. Foi observado que o vírus é sensível à temperatura e às condições do meio, como incidência da radiação solar, concentração de amônia etc. Com relação às tecnologias de tratamento, embora a desinfecção seja a etapa primordial para inativação do patógeno, algumas tecnologias de tratamento secundário, notadamente MBR e Lagoas de Estabilização, podem auxiliar na remoção de patógenos virais. Por fim, o trabalho mostrou a maior presença de fármacos à base de cloroquina, os quais têm sido utilizados no combate à doença e podem ser tóxicos a sistemas anaeróbios, principal rota de tratamento de esgoto sanitário do Brasil. Diante do novo cenário no país, é necessário que as ETEs passem por readequações, tendo em vista a maior concentração do patógeno SARS-CoV-2.

Palavras-chave: Tratamento de esgoto. Coronavírus. Desinfecção. 
radiation, ammonia concentration, etc. Regarding treatment technologies, although disinfection is the primary step for inactivating the pathogen, some technologies at the secondary level, notably MBR and Stabilization Ponds, can assist in the removal of viral pathogens. Finally, the study showed that the greater presence of chloroquine-based drugs, which have been used to combat the disease, can be toxic to anaerobic systems, the main route of sanitary sewage treatment in Brazil. Because of the new scenario in the country, the WWTP must undergo readjustments given the greater concentration of the SARS-Cov-2 pathogen.

Keywords: Wastewater treatment. Coronavírus. Disinfection.

\section{Resumen}

El mundo está sufriendo con una de las pandemias más fuertes de la historia, causada por el virus SARS-Cov-2. Hasta ahora, son cerca de nueve millones y siete mil de infectados en el mundo. Aunque no haya informes conclusivos sobre la transmisión feco-oral del Coronavirus entre personas, se cree que este tipo de transmisión es posible, visto que el SARS-Cov-2 ya fue encontrado en efluentes domésticos y en heces de pacientes. Este trabajo realizo una revisión de literatura evaluando la supervivencia del virus de la familia Coronaviridae a través del alcantarillado sanitario, sea por la presencia del efluente (cadena líquida), sea por la presencia en el fango de la estación de tratamiento de efluentes, que podrán causar contaminaciones por manejo inadecuado de los desechos producidos en el sistema de tratamiento. Fue observado que el virus es sensible a la temperatura del medio, como incidencia de la radiación solar, concentración de amoniaco, etc. Con relación a las tecnologías de tratamiento, aunque la desinfección sea la principal fase para inactivación del patógeno, algunas tecnologías a nivel secundario, como MBR y 'Lagunas de Estabilización', pueden ayudar en la remoción de patógenos virales. Por fin, el trabajo mostró que la mayor presencia de fármacos a base de Cloroquina, que se están utilizando en el tratamiento de la enfermedad, puede ser tóxica a los sistemas anaerobios, principal ruta de tratamiento de alcantarillado sanitario de Brasil. Ante el nuevo escenario del país, es necesario que las ETEs pasen por readaptaciones mirando la mayor concentración del patógeno SARS-Cov-2.

Palabras-clave: Tratamiento de alcantarillado sanitario. Coronavirus. desinfección.

\section{Résumé}

Le monde souffre de l'une des pandémies les plus fortes de l'histoire, causée par le virus du SRAS-CoV-2. Jusqu'à présent, on rapporte environ neuf millions et sept mille d'infectés dans le monde. Bien qu'il n'existe pas de rapport concluant sur la transmission feco-orale du coronavirus chez les personnes, on croit que ce type de transmission est possible, puisque le SRAS-Cov-2 a déjà été détecté dans les effluents domestiques et dans les excréments des patients. Ce travail a mené une revue documentaire pour évaluer la survie des virus coronaviridae par les eaux usées: soit par la présence dans les effluents (courant liquide), soit par la présence dans les boues de la station d'épuration. Ces présences peuvent causer des contaminations par une gestion inadéquate des résidus produits dans le système de traitement. On a observé que le virus est sensible à la température et aux conditions de l'environnement, telles que l'incidence du rayonnement solaire, la concentration d'ammoniac, etc. En ce qui concerne les technologies de traitement, bien que la désinfection soit la principale étape de l'inactivation des agents pathogènes, certaines technologies au niveau secondaire, notamment le MBR et les bassins de stabilisation, peuvent aider à éliminer les agents pathogènes viraux. Enfin, l'étude a montré que la plus grande présence de médicaments à base de chloroquine, qui ont été utilisés pour lutter contre la maladie, peut être toxique pour les systèmes anaérobies, la principale voie de traitement des eaux usées sanitaires au Brésil. Compte tenu du nouveau scénario dans le pays, il est nécessaire que les eaux usées subissent des réajustements à cause de la plus grande concentration de l'agent pathogène SRAS-Cov-2.

Mots clés: Traitement des eaux usées. Coronavirus. Désinfection. 


\section{Introdução}

O final de 2019 foi marcado por uma crise emergencial na saúde causada pelo vírus SARS-CoV-2, um tipo de coronavírus. A doença, nomeada de Covid-19, é caracterizada por uma síndrome respiratória aguda grave, a qual, em alguns casos, pode causar pneumonia. Esse surto surgiu pontualmente, na cidade de Wuhan, China, porém ganhou proporções mundiais e, ao final de junho de 2020, cerca de nove milhões e sete mil e pessoas estavam infectadas. A doença foi classificada como pandemia pela Organização Mundial da Saúde (OMS) e declarada emergência pública internacional (GORMLEY; ASPRAY; A KELLY, 2020; WHO, 2020).

As coronaviroses são causadas por uma família de vírus de envelope de fita simples de RNA, que se divide em quatro grandes gêneros: alfa coronavírus, beta coronavírus, gama coronavírus e delta coronavírus (FIGUEIREDO, 2020). A sequência de SARS-CoV-2 é 82\% semelhante ao SARS-CoV (CHAN, KOK; ZHU, 2020), que também causa uma síndrome respiratória aguda grave, sendo ambos pertencentes ao gênero $\beta$ da família Coronaviridae (WAN, et al., 2020). As doenças provocadas por esse tipo de vírus são conhecidas por causarem sintomas respiratórios e estomacais, como também é o caso da MERS-CoV, o qual causou a síndrome respiratória do Oriente Médio.

Estudos indicam que o surto global de SARS acontecido em 2002 e 2003 ocorreu por meio do contato direto entre pessoas, principalmente por contato com gotículas de secreções respiratórias de uma pessoa infectada (TSANG, et al., 2003; LEE et al., 2003; WHO, 2003a; CYRANOSKI; ABBOTT, 2003; POUTANEN, et al., 2003; DONNELLY, et al., 2003). Entretanto essa pode não ser a única forma de transmissão, sendo a via fecal-oral uma possibilidade real, mesmo não havendo a comprovação de que há casos de transmissão dessa forma entre pessoas (WHO, 2020).

Alguns autores levantaram a possibilidade de os sistemas de esgotamento sanitário atuarem como vetor dos microrganismos patogênicos causadores das coronaviroses. Em 2003, um relatório da OMS, constatou que um defeito na tubulação do sistema de esgotamento sanitário de um condomínio em Hong Kong pode ter facilitado o transporte do vírus causador da SARS através dos encanamentos dos banheiros (GORMLEY; ASPRAY; A KELLY, 2020).

Nesse sentido, Chan et al. (2004) demonstraram que o RNA do SARS-CoV foi detectado nas fezes dos pacientes a partir do quinto dia da doença, havendo aumento progressivo da proporção de amostras positivas, com o pico ocorrendo após o $11^{\circ}$ dia de infecção. Entretanto o RNA viral ainda se manteve presente nas fezes após 30 dias de doença.

Os estudos apresentados acima levantaram a suspeita de que o novo SARS-CoV-2 também poderia estar presente no esgoto. Xiao et al. (2020) avaliaram a presença e sobrevivência do SARS-CoV (vírus que causou o surto em 2003 e com características semelhantes SARS-CoV-2) em efluentes hospitalares. Os autores observaram a sobrevivência por até 14 dias em esgotos a 4 graus Celsius e de até 2 dias a 20 graus Celsius. Os fatos relatados pelos autores indicam que as águas residuárias podem ser uma fonte potencial de transmissão do vírus e a temperatura tem efeito considerável na capacidade de sobrevivência do patógeno.

A preocupação com a presença do patógeno no esgoto se agrava devido aos dados publicados por Holshue et al. (2020) e Xiao et al. (2020), em que foi verificada a presença de fragmentos de RNA do SARSCoV-2 em amostras de fezes de pacientes já curados. Esse resultado aponta para a possibilidade de uma grande concentração do vírus no esgoto advindo de pacientes sintomáticos, assintomáticos e pacientes já curados. No caso destes últimos, ainda não está claro por quanto tempo o vírus pode estar presente nas fezes.

Segundo o Diagnóstico Nacional dos Serviços de Água e Esgoto (BRASIL, 2016), apenas 40,8\% da vazão de esgoto gerada no país é tratada. O cenário do país é agravado quando se observa que a maior parte das ETEs do país apresentam diversas patologias (problemas relacionados à concepção e projeto, estrutura, operação etc.) comprometendo o seu rendimento. O estudo realizado por Oliveira e Von Sperling (2005) avaliou o rendimento de mais de cem ETEs no Brasil, das mais diversas tecnologias, e concluiu que muitas estações apresentaram eficiências de remoção aquém do reportado na literatura. Por exemplo, citam os resultados 
observados nas ETEs com reatores do tipo UASB, os quais, quando operados isoladamente, apresentaram um desempenho abaixo do esperado em termos de concentrações de DQO, remoção de nutrientes e de coliformes fecais. É importante ressaltar que, segundo levantamento realizado por Chernicharo et al. (2018), o país detém o maior parque de reatores UASB no mundo.

Os resultados mostrados acima ressaltam a necessidade de uma avaliação integrada sobre as possibilidades da transmissão do coronavírus através do esgotamento sanitário no Brasil. Embora até o presente momento não tenha sido relatada a existência de casos com transmissão fecal-oral do novo coronavírus no mundo (WHO, 2020), muitos estudos mostram que é possível que ocorra essa transmissão, especialmente em países subdesenvolvidos, com baixa cobertura de saneamento ambiental.

Nessa perspectiva, este trabalho avaliou o estado da arte sobre pesquisas relacionadas à sobrevivência dos vírus da família Coronaviridae através do esgoto, seja pela presença no efluente (corrente líquida), seja pela presença no lodo de ETEs, os quais poderão causar contaminações pelo manejo inadequado dos resíduos produzidos no sistema de tratamento. Adicionalmente, este estudo apresenta as principais operações unitárias em ETEs que podem inativar o patógeno em correntes líquidas.

\section{Doenças de veiculação hídrica e a presença de vírus no esgoto sanitário}

As doenças de veiculação hídrica geralmente são transmitidas pelo consumo de água contaminada pela rota fecal-oral. A ocorrência dessas doenças se dá pela presença de águas que receberam, direta ou indiretamente, dejetos fecais contendo cistos e oocistos de protozoários, ovos de helmintos, bactérias patogênicas e patógenos virais. Entre os patógenos responsáveis pelas inúmeras doenças de veiculação hídrica, os vírus merecem destaque, devido à sua alta resistência aos fatores ambientais e à possibilidade de se manterem ativos no meio mesmo após tratamento de água e esgoto (BOSCH et al., 2008).

A literatura relata que a concentração de vírus no esgoto depende, principalmente: (i) da carga viral da doença na população, (ii) da composição do esgoto, o qual pode favorecer ou não a sobrevivência do patógeno, (iii) da temperatura, (iv) dos tratamentos adequados do esgoto e (v) da disposição final dos esgotos tratados, o qual pode ser realizado em rios, solo, disposição oceânica etc. (METCALF et al., 1995). A água e o esgoto podem estar contaminados por centenas de tipos de vírus entéricos humanos, os quais são excretados em grande número nas fezes de pacientes infectados (BOSCH et al., 2008). Com o intuito de exemplificar, cita-se que indivíduos com diarreia ou hepatite podem excretar de 105 a 1.011 partículas virais por grama de fezes. Além das fezes, outra via que pode ocasionar elevada quantidade de vírus em sistemas de esgotamento sanitário é o vômito. Estudos mostraram que um indivíduo infectado por norovírus elimina, aproximadamente, 30 milhões de partículas virais durante um evento de vômito (BOSCH et al., 2008).

Nesse sentido, a Tab. (1) mostra os principais patógenos virais que podem estar presentes no esgoto bruto e suas respectivas concentrações.

Tabela 1 - Principais patógenos que podem ser encontrados em esgoto bruto e concentrações.

\begin{tabular}{l|c|c}
\hline Patógeno & Número de microrganismos por grama de fezes & Número/100 $\mathbf{~ L ~ d e ~ e s g o t o ~}$ \\
\hline Adenovírus & $10^{10}$ & Sem registro \\
\hline Coronavírus & $10^{5^{*}}$ & $100^{\star *}$ \\
\hline Enterovírus & $10^{3}-10^{7}$ & $180-500.000$ \\
\hline Hepatite A & $10^{8}$ & Sem registro \\
\hline Norovírus & $10^{12}$ & Sem registro \\
\hline Rotavírus & $10^{10}$ & $400-85.000$ \\
\hline
\end{tabular}

Fonte: Adaptado de Garrafa, 2009. "Zhang et al. (2020); "Wu et al. (2020). 
Inúmeros estudos documentaram a presença de vírus em água de abastecimento bruta e tratada, em esgoto doméstico e no lodo de estações de tratamento de esgoto (ABBASZADEGAN et al,. 1999; GARRAFA, 2009; SASSAROLI, 2002). Nessas pesquisas observou-se grande resistência de alguns vírus aos fatores ambientais e aos diversos tratamentos físico-químicos empregados no tratamento de água para abastecimento e também ao tratamento biológico de esgotos sanitários (ESTES et al., 1979; PAULI, 2003; RAO; MELNICK, 1986).

O conjunto dos fatores citados acima mostra o risco de contaminação dos seres humanos a vários patógenos pela rota fecal-oral, a qual pode ocorrer em diferentes formas, direta ou indiretamente (GARRAFA, 2009). Dessa forma, observa-se que é indispensável um sistema de esgotamento sanitário e de tratamento de esgoto de forma que o patógeno seja eliminado antes de alcançar um corpo hídrico, tendo em vista que as águas desses mananciais podem ser utilizadas de diversas formas, como para o abastecimento humano, o cultivo de alimentos, a recreação, a pesca, o que amplia as possibilidades de contaminação (METCALF; EDDY, 2003).

A principal contribuição de vírus e patógenos nas redes de esgotamento é oriunda de domicílios e hospitais. Embora alguns autores recomendem que os sistemas públicos e privados de saúde tenham um sistema próprio de tratamento, observa-se que essa ainda não é a realidade brasileira, pois muitas unidades de saúde interligam os esgotos sanitários diretamente na rede.

Os sistemas de tratamento de esgoto sanitário são compostos por diferentes níveis, visando a remoção de componentes específicos. No caso específico da remoção de patógenos, embora possam ser removidos ao longo dos processos de tratamento, é importante destacar que a etapa de desinfecção é a principal via de inativação desses poluentes. Nesse sentido, a Fig. 1 mostra o esquemático dos níveis de tratamento de uma ETE, dando enfoque na etapa de desinfecção, a qual será abordada neste trabalho.

Figura 1 - Fluxograma de possibilidades de contaminação por Covid-19.

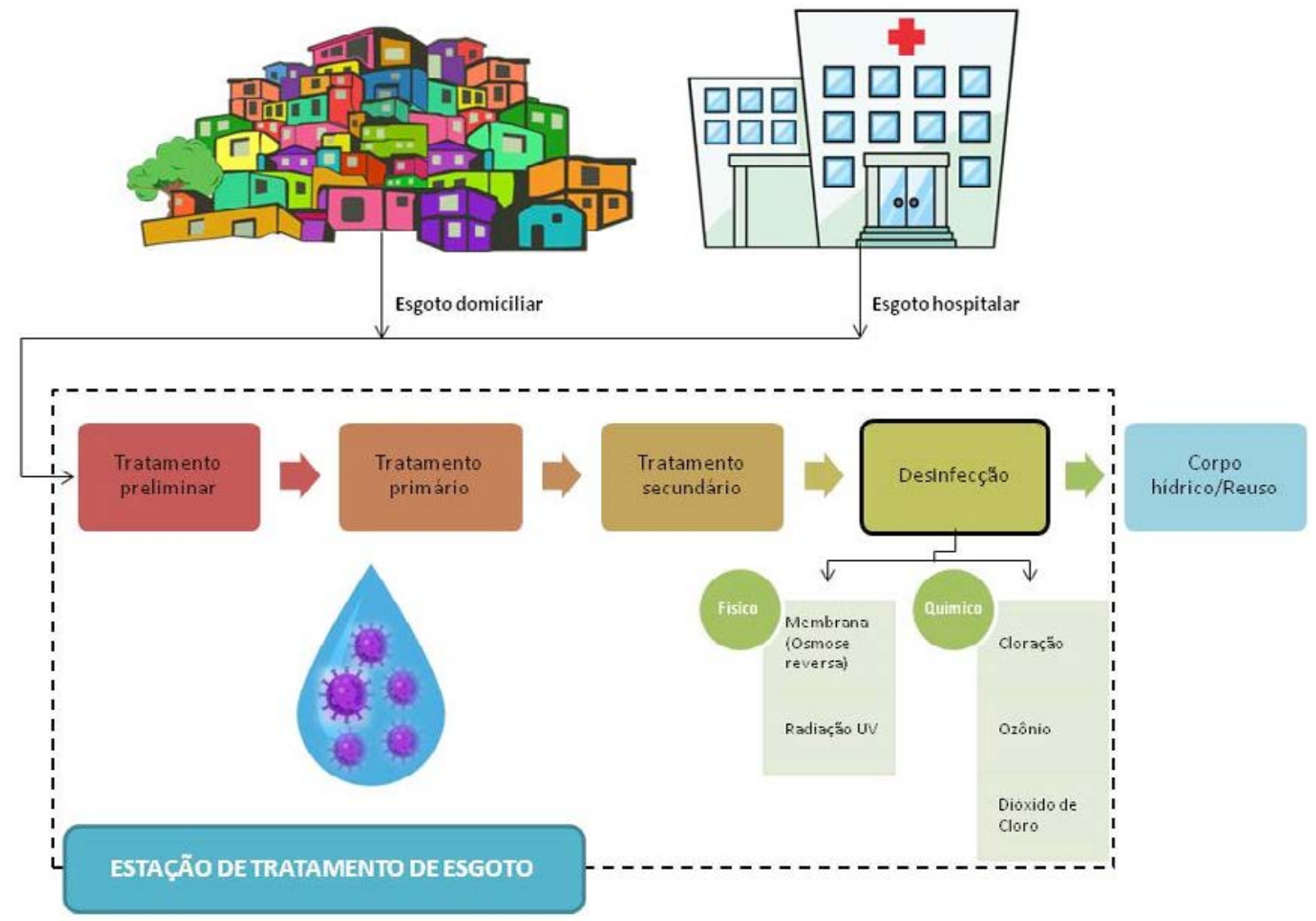

Fonte: Elaborado pelos autores, 2020. 


\section{Sobrevivência nas correntes líquidas de esgoto sanitário}

As informações sobre o potencial de transmissão pelo meio ambiente do novo coronavírus são muito limitadas até o momento. No entanto alguns estudos mostram que a veiculação hídrica pode ser possível, principalmente devido ao aumento da concentração do patógeno nas correntes líquidas, decorrente do maior número de infectados.

Em 2009, um amplo estudo elaborado por Gundy et al. (2008) mostrou que os coronavírus podem permanecer ativos nas fezes, indicando a possibilidade do novo coronavírus estar presente no esgoto (WANG et al. 2005).

O fato de o SARS-CoV poder se replicar no sistema entérico (LEUNG et al. 2004) torna-o um possível patógeno entérico, cuja incidência de diarreia varia de 8 a 73\% em casos de SARS, o que aumenta a preocupação quanto ao seu potencial de transmissão. Chan et al. (2004) e Liu et al. (2004) também observaram a presença do patógeno a partir de fezes de pacientes com SARS até 3 semanas após a infecção. Ressalta-se que o novo coronavírus é $82 \%$ semelhante ao SARS-CoV.

Os agravantes sobre a prevalência do novo coronavírus em sistemas hídricos foram apresentados no recente estudo elaborado por Medema et al. (2020), em que foram analisados dois hospitais na Holanda, os quais indicaram que o SARS-CoV-2 já circulava nas redes de esgotamento sem que houvesse pacientes diagnosticados. O estudo mostrou que é possível que pessoas infectadas assintomáticas também eliminem o patógeno nas excretas, agravando o cenário. O estudo também mostrou a possibilidade de se utilizar o monitoramento do vírus no esgoto como uma ferramenta de avaliação da presença do vírus em municípios que possuem sistemas descentralizados de esgoto.

Em estudo elaborado por Wu et al. (2020), foi observada elevada concentração do vírus nas correntes de esgoto de uma ETE localizada em Massachusetts. Os autores observaram um elevado pico na concentração, principalmente no período de 18 a 25 de março de 2020. Ressalta-se que a doença pode causar diarreia em alguns pacientes, aumentando a concentração do vírus em alguns períodos. Os autores evidenciaram a importância da realização de estudos para modelar a concentração do vírus no esgoto em função do número de infectados. Também foi destacado que o monitoramento do vírus nas correntes líquidas deve ser utilizado como uma abordagem complementar para medir a presença de infectados em determinada região, especialmente em cidades onde ainda não houve a contabilização dessas pessoas.

Em 2017, foi realizado um experimento em larga escala na tubulação de esgoto entre dois andares de um prédio. Foi utilizado um equipamento de teste para canalização de águas residuárias e o microrganismo Pseudomonas putida como modelo. O teste mostrou que é possível a transmissão de patógenos entre quartos de diferentes andares de um prédio pelo fluxo de ar do sistema de esgotamento (GORMLEY; ASPRAY; A KELLY, 2020). O ar contaminado poderia passar por todo o edifício através da tubulação sem nenhuma barreira. A maior preocupação é para locais que tenham grande concentração de pessoas contaminadas, como hospitais, visto que a carga viral transmitida pode ser maior. Dessa forma, a ventilação do sistema de esgotamento sanitário pode ser um meio de transmissão, o que traz a maior preocupação com as EEE, em que, habitualmente, há desprendimento de gases. Dessa forma, caso o operador não esteja utilizando equipamento de proteção individual, pode haver a contaminação (GORMLEY; ASPRAY; A KELLY, 2020; WHO, 2020):

\section{Fatores intervenientes na sobrevivência do vírus no esgoto}

Diversos fatores podem influenciar a sobrevivência de vírus nas correntes de esgoto, tais como: temperatura, $\mathrm{pH}$ e radiação solar. Altas temperaturas e extremos valores de $\mathrm{pH}$ podem inativar vírus, desnaturando suas proteínas e ácidos nucleicos (ROMERO et al., 2011). A intensidade e o tempo em que esses microrganismos estão expostos são vitais para a sobrevivência ou não do patógeno.

O coronavírus é do tipo envelopado, ou seja, possui uma camada lipídica protetora. De forma geral, esse tipo de patógeno, que pode contaminar seres humanos, existe em baixas concentrações nas fezes e rapidamente são inativados no ambiente aquoso. Entretanto evidências mostraram que os genes desses vírus 
foram detectados nas fezes de indivíduos contaminados e no lodo de descarte de estações de tratamento de esgoto (YE; ELLENBERG; GRAHAM; WIGGINTON, 2016).

Conforme Who (2020), o SARS-CoV-2 é um vírus envelopado que possui uma frágil membrana, por isso, de modo geral, é menos estável no ambiente e mais suscetível a oxidantes como o cloro. Por exemplo, estudos mostraram que o patógeno sobrevive dois dias em água tratada sem cloro e em esgoto hospitalar a $20^{\circ} \mathrm{C}$. Além disso, são muito sensíveis ao calor, pH extremo, luz solar e desifetantes comuns, facilitando a inativação. Desse modo, as características dos efluentes irão influenciar na sobrevivência do vírus.

Fatores como temperatura, exposição à luz, matéria orgânica e presença de outros microorganismos são fatores que afetam a sobrevivência do coronavírus (NADDEO; LIU, 2020; GUNDY et al., 2008). A temperatura é um dos principais fatores que influenciam na sobrevivência do vírus, porque causa desnaturação das proteínas e aumenta a atividade das enzimas extracelulares. O efeito do calor pode ser explicado com base na agregação térmica da membrana de proteína, que pode ser desnaturada em 10 minutos a $55^{\circ} \mathrm{C}$ (WANG et al., 2004). Estudos realizados por Gundy et al. (2008) mostraram para que três vírus, a saber, FIPV (ATCC990), HCoV (ATCC 740 e MRC-5 (ATCC 171), sendo os dois primeiros da família Coronavidae e o terceiro um vírus entérico, a inativação ocorreu mais rapidamente na temperatura de $23^{\circ} \mathrm{C}$ do que na de $4^{\circ} \mathrm{C}$. A mesma relação foi encontrada por Casanova, Rutala, Weber e Sobsey (2009).

Em adição, o levantamento realizado por Günter, Voss e Scheithauer (2020) mostrou que, de um total de 10 (dez) estudos avaliados, o aumento de temperatura reduz o tempo de contato (desinfecção) necessário para reduzir a infectividade do vírus em até $4 \log 10$.

Baseado nesse aspecto e considerando que o tempo de residência do efluente doméstico no sistema de esgotamento, de modo geral, é de menos de 24 horas, deve-se ter atenção, principalmente em climas frios, com a presença de vírus nos efluentes, pois vírus excretados em fezes e urina podem chegar de forma ativa nas ETEs (YE; ELLENBERG; GRAHAM; WIGGINTON, 2016).

Outro fator influente é a presença de matéria orgânica e sólidos suspensos, que pode servir como proteção contra a inativação química e biológica ao se adsorver as partículas, mas pode servir como mecanismo de remoção quando o material sólido sedimenta (GUNDY et al., 2008). Um estudo mostrou que, para o coronavírus, os sólidos funcionaram como uma proteção, pois tanto na amostra de água quanto de efluente primário não filtrado o tempo de inativação foi maior quando comparada com amostra filtrada. Os micro-organismos funcionam como predadores, por exemplo, protozoa. Isso aumenta a taxa de inativação. Comparando os efluentes não filtrados primários e secundários, o primeiro apresenta taxa de inativação maior, o que indica que os sólidos associados aos vírus funcionam como uma proteção à inativação e predação (GUNDY et al., 2008).

Nesse sentido, é possível que vírus envelopados excretados nas fezes humanas ou na urina possam sobreviver em ambientes aquosos por um período de tempo relevante para o tratamento de água e esgoto (WIGGINTON; YE; ELLENBERG, 2015; WOLFF; SATTAR; ADEGBUNRIN; TETRO, 2005). Tendo em vista a falta de saneamento no Brasil, principalmente em termos de esgotamento sanitário, é necessário intensificar os cuidados, visto que um elevado percentual do esgoto coletado não é tratado, sendo despejado em corpos hídricos que, por vezes, são usados para captação de água para abastecimento.

\section{Tecnologias de tratamento para remoção/inativação do coronavírus}

As águas residuais domésticas contêm vários patógenos que, se não forem suficientemente eliminados, podem entrar nos corpos de água receptores e causar doenças transmitidas pela água. Entre os patógenos transmitidos pela água, os vírus podem ocorrer, sobreviver e decair de maneira muito diferente das bactérias (ZHANG et al., 2016).

A maioria das tecnologias empregadas em nível secundário de tratamento de esgoto não é projetada para eliminação de vírus, mas para remoção de sólidos em suspensão (SS), matéria orgânica, e em alguns casos, a remoção de nutrientes. No entanto, como os vírus podem ser vistos como partículas finas com características 
coloidais (CAO H et al., 2010; WONG et al. 2012b), eles podem ser adsorvidos em partículas suspensas e removidas com o lodo em excesso (XAGORARAKI et al., 2014; TEMPLETON et al., 2008).

Dessa forma, embora a desinfecção dos esgotos sanitários seja a etapa destinada prioritariamente à remoção de patógenos (entre eles, os vírus), observa-se que pode ocorrer a eliminação de vírus durante a remoção de partículas sólidas, antes do estágio da desinfecção (HAO et al., 2010).

Kitajima et al. (2014) relataram remoções de alguns vírus entre 0,6 e 2,8 log quando aplicou-se o processo convencional de lodo ativado (antes da desinfecção). Acredita-se que a remoção do vírus nesse processo é, principalmente, devido à separação dos flocos de lodo do líquido sobrenadante.

Entre todas as tecnologias de tratamento secundário de esgoto, o método de maior reconhecimento na literatura para remoção de patógenos são as lagoas de estabilização, principalmente as lagoas facultativas e as lagoas de maturação. As primeiras são uma tecnologia simples e prática que possibilita a destruição de patógenos devido ao elevado tempo de detenção hidráulica combinado com luz solar, pH elevado e atividade biológica.

Shuval et al. (1986), Shuval (1990) e Drechsel et al. (2010) relataram que a remoção de vírus em um sistema de lagoas de estabilização com TDH de 20 dias, com temperaturas acima de $20^{\circ} \mathrm{C}$, pode apresentar remoção de vírus de 2 a 4 log. Os fatores que favorecem a alta remoção desses patógenos em lagoas são: (i) sedimentação com o lodo de fundo, (ii) elevado pH em lagoas facultativas e maturação, (iii) alta radiação solar e temperatura e (iv) predação por organismos de níveis tróficos mais altos (VERBYLA et al., 2015).

Outra tecnologia de tratamento de esgoto em nível secundário que apresenta significativa remoção de patógenos é o biorreator de membrana (MBR). Nesses sistemas, o mecanismo básico de eliminação do vírus pode ser considerado como exclusão de tamanho. A literatura relata que a membrana de ultrafiltração (UF) é suficiente para a eliminação física da maioria dos vírus. Lovins et al. (2002) relataram que a UF poderia atingir até 5 log de remoção de vírus.

Embora os processos de tratamento secundário possam causar uma redução na concentração de vírus nas correntes de esgoto, cita-se que a etapa terciária de tratamento, notadamente a filtração e principalmente a desinfecção, são os processos de maior eficiência na remoção de patógenos de um sistema de tratamento de esgoto.

A filtração em filtros de areia pode remover de 10 a $98 \%$ dos vírus. No entanto esses valores podem ser ainda maiores quando coagulantes são adicionados antes do filtro de areia para melhorar o processo de adsorção (SHIRASAKI et al., 2010). Deve-se notar que, quando ocorre a remoção por sedimentação ou filtração, o vírus é transportado apenas para os sedimentos (lodo), mas não necessariamente é inativado.

Por conta disso, é necessária uma etapa de estabilização do lodo, como caleação, compostagem, tratamento térmico e digestão anaeróbica mesófila. A desidratação e secagem mecânica podem eliminar vírus com eficiências de até 1 log, rompendo o capsídeo do vírus e liberando ácido nucleico (MONPOEHO et al., 2004). O processo de calagem (ou caleação), combinado com um pH alto, pode diminuir a concentração dos vírus em, pelo menos, 4 log. Esse processo é amplamente utilizado quando se visa a compostagem, em que temperaturas de $55-70{ }^{\circ} \mathrm{C}$ são atingidas durante o processo, sendo suficientemente altas para eliminar a maioria dos vírus. O tratamento térmico, por sua vez, claramente tem a mais alta eficiência de inativação, com valores de remoção próximos de 5 log. Por outro lado, a digestão anaeróbica mesófila geralmente tem baixo poder de desinfecção, com redução de 1 log para vírus (MONPOEHO et al., 2004; GUZMAN et al., 2007).

Conforme apresentado acima, algumas tecnologias de tratamento secundário apresentam notáveis remoções de vírus, destacando-se lagoas de estabilização e reatores do tipo MBR. No entanto é na desinfecção que ocorre a maior parcela da inativação dos microrganismos, a qual é realizada por intermédio de agentes físicos e/ou químicos.

Por mais que na etapa secundária de tratamento possa haver uma redução dos microrganismos patogênicos através da agregação às partículas coloidais, esse mecanismo não é o objetivo principal dos sistemas biológicos. 
A ação dos desinfetantes sobre os microrganismos pode se dar três mecanismos:

- Destruição ou danificação da estrutura da célula. Nesse caso, o desinfetante atua sobre os constituintes da parede celular, os quais são danificados ou, até mesmo, destruídos. Também é possível, nesse mesmo mecanismo, que o desinfetante se combine com os ácidos nucleicos e, assim, altere o metabolismo do patógeno;

- Interferência no nível energético do metabolismo. Esse mecanismo ocorre quando o desinfetante inativa as enzimas, dificultando a obtenção de energia para a célula, o que leva ao declínio desta;

- Interferência na biossíntese (ou anabolismo). Nesse caso, há uma combinação de vários mecanismos inibindo a produção de enzimas e RNA envolvidos no crescimento do microrganismo.

Os desinfetantes químicos (cloro, dióxido de cloro, cloramina e ozônio) ocasionam danos ao capsídeo viral, enquanto a irradiação por UV afeta principalmente a estrutura do código genético (estrutura dos ácidos nucleicos) dos vírus.

Quando o cloro é usado para desinfecção, o agente eficaz dos vírus inativos é o ácido hipocloroso, que pode danificar as funções mediadas pelo genoma e pelas proteínas (WIGGINTON; KOHN, 2012). A dose de cloro $(C)$ e o tempo de contato $(t)$ governam o resultado da inativação do vírus. A dose inicial típica de cloro é de 5 a $20 \mathrm{mg} / \mathrm{L}$ e o tempo de contato é de 30 a 60 minutos para a desinfecção do efluente secundário. Alguns estudos relataram (Li et al., 2011) a total remoção de vírus quando a dose de cloro foi superior a $10 \mathrm{mg} / \mathrm{L}$ e o tempo de contato de $60 \mathrm{~min}$. Todavia ressalta-se que a eficiência da desinfecção também depende da concentração de sólidos em suspensão no efluente final (METCALF; EDDY, 2003).

O dióxido de cloro e a cloramina também são desinfetantes alternativos e, nesses casos, os vírus são inativados principalmente devido a danos no capsídeo viral (WIGGINTON; KOHN 2012). O dióxido de cloro é mais eficaz na desinfecção do que o cloro, enquanto a cloramina é um desinfetante menos eficaz (JUNLI et al., 1997). O efeito da cloração pode ser fortemente afetado pela existência de várias formas de nitrogênio e substâncias orgânicas residuais no efluente secundário. A formação de subprodutos de desinfecção (THMs) também é um fator que restringe sua aplicação.

Um oxidante que também tem se mostrado eficaz na desinfecção de patógenos é o ozônio, atacando o material da proteína viral (WIGGINTON; KOHN 2012). O ozônio pode reagir com a água para produzir radicais que depois destroem ainda mais os ácidos nucleicos virais. Comparado ao cloro, o ozônio tem uma eficiência mais alta, no entanto há desvantagens relacionadas com o custo operacional mais alto e a necessidade de realizar contínuas dosagens de ozônio, pois é altamente instável, permanecendo ativo por pouco tempo. A dose inicial típica de ozônio é de 3 a $10 \mathrm{mg} / \mathrm{L}$ e o tempo de contato é de $10 \mathrm{~min}$, o que resulta em valores de Ct entre 30 e $100 \mathrm{mg}$ min/L, muito mais baixos que com a cloração (PARASKEVA; GRAHAM, 2002).

A desinfecção ultravioleta (UV) é considerada uma solução eficaz e competitiva para a desinfecção de efluentes secundários, devido ao fato de não haver adição de agentes químicos, evitando problemas de corrosão e formação de subprodutos de desinfecção. No entanto o efeito de desinfecção pode ser significativamente prejudicado pela presença de sólidos suspensos no efluente a montante da unidade de desinfecção por UV.

Apesar de ser possível a sobrevivência do coronavírus na água potável, é importante ressaltar que ainda não há evidências da sua presença nas fontes de água superficiais ou subterrâneas ou contaminação através da água potável. Em relação às ETE, no surto de SARS que ocorreu entre 2002 e 2003, na China, não foi reportada a contaminação de trabalhadores (WHO, 2020). No entanto, tendo em vista que a atual pandemia do novo coronavírus se trata da maior contaminação viral humana no século 21 , são recomendadas as seguintes medidas:

(i) Uso de equipamentos de proteção individual (EPI) pelos profissionais do saneamento, a fim de evitar contato com o esgoto e inalação de aerossóis;

(ii) Manter bons hábitos de higiene pessoal, como lavar as mãos com água e sabão, e desinfetar a roupa de trabalho; 
(iii) Não tocar face, olhos e boca antes de higienizar as mãos;

(iv) Manter o local de trabalho higienizado e desinfetado após uso.

Ressalta-se, todavia, que é necessário cuidado em toda a rede esgotamento sanitário, pois, conforme Ye, Ellenberg, Graham, Wigginton (2016), apesar dos vírus envelopados serem rapidamente inativados na etapa da desinfecção, eles sobrevivem tempo suficiente para ser motivo de atenção nas instalações de ETE. Nesse sentido, vários autores ressaltam a importância de estudos para avaliar melhor o tempo de sobrevivência desse vírus e sua capacidade de reprodução no lodo de ETEs (YE; ELLENBERG; GRAHAM; WIGGINTON, 2016).

\section{Desafios}

Diante do contexto atual da pandemia no Brasil, alguns desafios são apresentados no panorama do tratamento de esgoto do país:

(i) Na maioria das estações de tratamento de esgotos sanitários do Brasil inexistem processos de desinfecção e, quando existem, dá-se, comumente, por meio de cloração do efluente produzido no tratamento secundário. No entanto em muitas ETEs essa etapa é feita sem o controle adequado da dosagem e do tempo de contato, tendo em vista que muitos tanques de contato (cloração) foram dimensionados com vazões inferiores às atuais, ocasionado uma redução do TDH. Dessa forma, imediatamente, deve ser revista a operação de desinfecção das ETEs com cloração, de forma a aprimorar a operação unitária, tendo em vista uma maior eficiência na desinfecção do patógeno;

(ii) A descoberta que a interação do cloro com a matéria orgânica produz subprodutos da desinfecção, entre eles os trihalometanos (THMs), presumidos como carcinogênicos (BAIRD, 2011), estimulou a procura por desinfetantes alternativos, passando-se a utilizar principalmente a radiação ultravioleta. No entanto essa tecnologia é praticamente inviável quando a concentração de sólidos suspensos é maior que $30 \mathrm{mg} / \mathrm{L}$. Estudos desenvolvidos pelo PROSAB mostraram boa inativação de patógenos com efluentes com concentração de SS abaixo de $20 \mathrm{mg} / \mathrm{L}$. Essa questão pode ser um entrave para as tecnologias convencionais de tratamento, como reatores UASB, lagoas de estabilização, lodos ativados etc., os quais dificilmente apresentam concentração de SS abaixo de $50 \mathrm{mg} / \mathrm{L}$. Dessa forma, as ETEs que possuem desinfecção por radiação UV devem avaliar de forma integral a performance do sistema, tendo em vista a influência da qualidade do efluente pós-tratamento secundário na etapa posterior de desinfecção.

(iii) O aumento do uso de fármacos, devido ao elevado número de pessoas em tratamento, além do crescimento da automedicação, são fatores que devem ser considerados no tratamento de água e esgoto. Além de não serem facilmente detectáveis, as tecnologias de tratamento predominante no Brasil não degradam esses poluentes, apesar de vários estudos terem sido realizados com essa temática. (AHMAD; NAEEM; AHMAD; USMAN; AL-WABEL, 2019; BISOGNIN; WOLFF; CARISSIMI; PRESTES; ZANELLA, 2019; BUARQUE; FIRMINO; SANTOS, 2019).

(iv) Ainda na discussão apresentada no tópico acima, alguns estudos têm alertado que o uso de alguns fármacos utilizados no tratamento da doença Covid-19 pode afetar significativamente o desempenho de sistemas anaeróbios de tratamento. Chen et al. (2020) mostraram que a maior presença de fármacos à base de cloroquina inibiu os reatores anaeróbio, reduzindo a remoção de matéria orgânica (na forma DQO), mostrando que esses sistemas são facilmente afetados pela maior presença do fármaco. Portanto, é necessário que se avalie o uso de reatores anaeróbios em sistemas que possam receber maior carga de fármacos utilizados no combate ao coronavírus, tendo em vista que podem ser suscetíveis à perda de performance.

(v) Um dos fatores a se considerar são metodologias de detecção, principalmente em termos quantitativos. Há muitas técnicas para vírus não envelopados (Ye et al. 2016), porém o mesmo não ocorre para 
os envelopados, como o coronavírus. Todavia, estão sendo desenvolvidas metodologias de análise qualitativa simplificada através de biomarcadores (MAO; ZHANG; YANG, 2020). Detectar o vírus no esgoto permite analisar qual área está sendo infectada e o planejar medidas para evitar o espalhamento do vírus. Além disso, possibilita ter um valor mais aproximado dos infectados, visto que alguns são assintomáticos e alguns países não possuem capacidade de testar uma grande quantidade de pessoas (WU; XIAO; ZHANG; GU; LEE; KAUFFMAN; HANAGE; MATUS; GHAELI; ENDO, 2020).

\section{Conclusão}

Embora não haja relato conclusivo sobre a transmissão fecal-oral do SARS-CoV-2 entre pessoas, acredita-se que esse tipo de transmissão seja possível. A preocupação sobre a presença do patógeno no esgoto se agrava devido ao fato de alguns pacientes já curados, e até mesmo pacientes assintomáticos, excretarem fragmentos de RNA do SARS-CoV-2 nas fezes, o que aumenta consideravelmente a concentração no patógeno. Diante do novo cenário no país, recomenda-se que as ETEs passem por readequações, tendo em vista a melhora do processo de desinfecção. Também destacase a necessidade de maiores cuidados quanto à gestão do lodo das ETEs e na operação das plantas de tratamento, pois gotículas contendo o patógeno pode ocasionar a contaminação dos operadores. Por fim, a transmissão do vírus através da veiculação hídrica deve ser estudada, pois se trata de um potencial meio de difusão da doença.

\section{Referências}

ABBASZADEGAN, M.; STEWART, P.; LeCHEVALLIER, M.; A strategy for detection of viruses in groundwater by PCR. Appl Environ Microbiol., [S. I.], v. 89, p. 283-291, 1999.

AHMAD, Jahangir; et al. A critical review on organic micropllutants contamination in wastewater and removal through carbon nanotubes. Journal of Environmental Management, [S. I.], v. 246, p. 214-228, 2019.

BAIRD, Colin. Química ambiental. Barcelona: Bookman, 2011.

BISOGNIN, Ramiro Pereira; WOLFF, Delmira Beatriz; CARISSIMI, Elvis; PRESTES, Osmar Damian; ZANELLA, Renato. Occurrence and fate of pharmaceuticals in effluent and sludge from a wastewater treatment plant in Brazil. Environmental Technology, [S. I.], v. 8, n. 1, p. 1-12, 17 dez. 2019. DOI: http:// dx.doi.org/10.1080/09593330.2019.1701561.

BOSCH, A; GUIX, S.; SANO, D.; PINTO, R. M. New tools for the study and direct surveillance of viral pathogens in water. Curr Opin Biotechnol, [S. I.], v. 19, p. 295-301, 2008.

BRASIL. Ministério das Cidades. Secretaria Nacional de Saneamento Ambiental. Sistema Nacional de Informações sobre Saneamento: diagnóstico dos serviços de água e esgotos - 2014. Brasília: MCIDADES, 2016. 212 p.

BUARQUE, Hugo Leonardo de Brito; FIRMINO, Paulo Igor Milen; SANTOS, André Bezerra dos. Enhanced removal of emerging micropollutants by applying microaeration to an anaerobic reactor. Engenharia Sanitaria e Ambiental, Rio de Janeiro, v. 24, n. 4, p. 667-673, jul./ago. 2019.

CAO H; TSAI, F.T.C.; RUSCH, K.A. Salinity and soluble organic matter on virus sorption in sand and soil columns. Ground Water, [S. I.], v. 48, n. 1, p. 42-52, 2018.

CASANOVA, Lisa; RUTALA, William A.; WEBER, David J.; SOBSEY, Mark D. Survival of surrogate coronaviruses in water. Water Research, [S. I.], v. 43, n.7, p. 1893-1898, 2009. 
CHAN, J. F W.; et al. Genomic characterization of the 2019 novel human-pathogenic coronavirus isolated from a patient with atypical pneumonia after visiting Wuhan. Emerg Microbes Infect, [S .I.] v. 9, n. 1, p. 221 236, 2020.

CHAN, P. K. S.; et al. Laboratory Diagnosis of SARS. Emerging Infectious Diseases, [S .I.] v. 10, n. 5, p. 825-831, 2004.

CHEN., N.; et al. Epidemiological and clinical characteristics of 99 cases of 2019 novel coronavírus pneumonia in Wuhan, China: a descriptive study. The Lancet, [S .I.], v. 395, n. 10223, p. 507-513, feb. 2020.

CHERNICHARO, C. A. de L.; et al. Panorama do tratamento de esgoto sanitário nas regiões Sul, Sudeste e Centro-Oeste do Brasil: tecnologias mais empregadas. Revista DAE, [S .I.], v. 66, n. 213, p. 5-19, 2018.

CYRANOSKI, D.; ABBOTT, A. Apartment complex holds clues to pandemic potential of SARS. Nature, [S .I.], v. 423, n. 6935, p. 3-4, 2003.

DONNELLY, C. A.; GHANIA, A C;, LEUNGB, G. M.; HEDLEYB, A. J.; FRASER, C.; RILEYA, S.; ABURADDADA, L. J.; HOB, L.-M.; THACHB, T.-Q.; CHAUB, P.; CHANB, K. P.; LAMB, T.-H.; TSEC, L.-Y.; TSANGC, T.; LIUD, S.-H.; KONGD, J. H. B.; LAUE, E. M. C.; FERGUSONA, N. M.; ANDERSONA, R. M. Epidemiological determinants of spread of causal agent of severe acute respiratory syndrome in Hong Kong. Lancet, [S .I.], v. 361, n. 9371, p. 1761-1766, 2003.

DRECHSEL P.; SCOTT C. A.; RASCHID-SALLY L.; REDWOOD M.; BAHRI, A. (ed.). Wastewater irrigation and health: assessing and mitigation risks in low-income countries. London: IDRC-IWMI, 2010.

ESTES, Mary Kolb; et al. Rotavirus stability and inactivation. Journal of General Virology, [S .I.], v. 43, n. 2, p. 403-409, 1979.

FIGUEIREDO, D.; SILVA, L.; BORBA-MIRANDA, L. COVID-19e m dados: Brasil em perspectiva comparada. Recife: MPCP, 2020.

GARRAFA, P. Avaliação da qualidade virológica do efluente doméstico tratado e disponibilizado para reuso na cidade de São Paulo 2009. Tese (Doutorado). Instituto de Ciências Biomédicas, Universidade de São Paulo, São Paulo, 2009.

GORMLEY, Michael; ASPRAY, Thomas J; A KELLY, David. COVID-19: mitigating transmission via wastewater plumbing systems. The Lancet Global Health, [S. I.], v. 8, n. 5, p. 643, 2020.

GUNDY P. M.; GERBA, C. P.; PEPPER, I. L. Survival of coronaviruses in water and wastewater. Food Environ Virol, [S .I.] 2008, v. 1, n. 1, p. 10.

GÜNTER, Kampf; VOSS, Andreas; SCHEITHAUER, Simon. Inactivation of coronaviruses by heat. Journal of Hospital Infection, [S. I.], v. 105, n. 2, p. 348-349, 2020.

GUZMAN, C.; JOFRE, J.; MONTEMAYOR, M.; LUCENA, F. Occurrence and levels of indicators and selected pathogens in different sludges and biosolids. J Appl Microbiol, [S. I.], v. 103, n. 6 p. 2420-2429, 2007.

HAO X. D.; WANG, Q. L.; ZHU, J. Y.; VAN LOOSDRECHT, M. C. M. Microbiological endogenous processes in biological wastewater treatment systems. Critical Reviews in Environmental Science and Technology, [S. I.], v. 40, p. 239-265, 2010.

HOLSHUE, M. L; et al. First case of 2019 novel coronavirus in the United States. N Engl J Med, [S. I.], v, 382, p. 929-936, 2020.

JUNLI, H.; LI, W.; NANQI, R.; FANG, M.; LIN, J.; XUELi, L.; RONGFANG, S.; QINGCHEN, T.; CHENGQUN, S.; WEIHONG, W.; GUANLE, Y. Disinfection effects of chlorine dioxide on viruses, algae and animal planktons in water. Environmental Chemistry, [S. I.], v. 15, n .4, p. 347-355, 1997. 
KITAJIMA, M.; IKER, B. C.; PEPPER, I. L.; GERBA, C. P. Relative abundance and treatment reduction of viruses during wastewater treatment processes-identification of potential viral indicators. Science of The Total Environment, [S. I.], v. 488-489, p. 290-296, 2014.

LEE, N.; HUI, D.; WU, A.; CHAN, P.; CAMERON, P.; JOYNT, G. M.; AHUJA, A.; YUNG, M.Y.; LEUNG, C. B.; TO, K. F.; LUI, S. F.; SZETO, C. C.; CHUNG, S., SUNG, J. J. Y. A major outbreak of severe acute respiratory syndrome in Hong Kong. NEJM, [S, I.], v. 348, p. 1986-1994, 2003.

LEUNG, G. M.; et al. SARS-CoV antibody prevalence in all Hong Kong patient contacts. Emerging Infectious Diseases, [S, I.], v. 10, n. 9, p. 1653-1656, set. 2004.

LI, D.; GU, A. Z.; ZENG, S.; YANG, W.; HE, M.; SHI, H. Evaluation of the infectivity, gene and antigenicity persistence of rotaviruses by free chlorine disinfection. J Environ Sci, [S, I.], v. 23, n. 10, p. 1691-1698, 2011.

LIU, Y. Q.; LIU, Y.; TAY, J. H. The effects of extracellular polymeric substances on the formation and stability of biogranules. Applied Microbiology Biotechnology, [S, I.], v. 65, n. 2, p. 143-148, 2004.

LOVINS, W. A.; TAYLOR, J. S.; HONG, S. K. Micro-organism rejection by membrane systems. Environ Eng Sci, [S, I.], v. 19, p. 453-465, 2002.

MAO, Kang; ZHANG, Hua; YANG, Zhugen. Can a Paper-Based Device Trace COVID-19 Sources with Wastewater-Based Epidemiology? Environ. Sci. Technol., [S, I.] v. 54, n. 7, p. 3733-3735, 2020.

MEDEMA, G.; et al. Title page presence of SARS-Coronavírus-2 in sewage . MedRxiv, 2020.

METCALF, L.; et al. Wastewater engineering: treatment and reuse. New York: McGraw-Hill, 2003.

METCALF, T. G.; MELNICK, J. L.; ESTES M. K. Environmental virology: from detection of virus in sewage and water by isolation by molecular biology - a trip of over 50 years. Ann Rev Microbiol., [S, I.], v. 49, p. 461-487, 1995.

MONPOEHO, S.; MAUL, A.; BONNIN, C.; PATRIA, L.; RANARIJAONA, S.; BILLAUDEL, S.; FERRE, V. Clearance of human-pathogenic viruses from sludge: study of four stabilization processes by real-time reverse transcription-PCR and cell culture. Appl Environ Microbiol, [S, I.], v. 70, n. 9, p. 5434-5440, 2004.

NADDEO, Vincenzo; LIU, Haizhou. Editorial Perspectives: 2019 novel coronavírus (SARS-CoV-2): what is its fate in urban water cycle and how can the water research community respond? Environmental Science:

Water Research \& Technology, [S. I.], n. 6, p. 1213-1216, 2020.

OLIVEIRA, S. M. A. C.; VON SPERLING, M. Evaluation of 166 treatment plants operating in Brazil, comprising several technologies. Part 1-performance analysis. Eng. Sanit. Ambient., [S. I.], p. 347-357, v.10, n. 4, 2005.

PARASKEVA, P.; GRAHAM, N.J.D. Ozonation of municipal wastewater effluents. Water Environment Research, [S, I.], v. 74, n. 6, p. 569-581, 2002.

PAULI, V. Ocorrência e distribuição de genótipos $\mathbf{G}$ e $\mathbf{P}$ de rotavírus em efluente doméstico e córrego da cidade de São Paulo. 2003. 121f. Dissertação (Mestrado em Microbiologia) - Instituto de Ciências Biomédica, Universidade de São Paulo. São Paulo, 2003.

POUTANEN, S. M.; LOW, D. E.; HENRY, B.; FINKELSTEIN, S.; ROSE, D.; GREE, K.; TELLIER R. N. R.; DRAKER, R.; ADACHI, D.; AYERS, M.; CHAN, A. K.; SKOWRONSKI, D. M.; SALIT, I.; SIMOR, A. E.; SLUTSKY, A. S.; DOYLE, P. W.; KRAJDEN, M.; PETRIC, M.; BRUNHAM, R. C.; MCGEER, A. J. Identification of severe acute respiratory syndrome in Canada. NEJM, [S, I.], v. 348, n. 20, p. 1995-2005, 2003.

RAO, V. Chalapati; METCALF, Theodore G.; MELNICK, Joseph L. Development of a method for concentration of rotavirus and its application to recovery of rotaviruses from estuarine waters. Applied And Environmental Microbiology, [S, I.], v. 52, n. 3, p. 484-488, 1986. 
ROMERO, O. C.; STRAUB, A. P.; KOHN, T.; NGUYEN, T. H. Role of temperature and Suwannee River natural organic matter on inactivation kinetics of rotavirus and bacteriophage MS2 by solar irradiation. Environmental Science \& Technology, [S, I.], v. 45, n. 24, p. 10385-10393, 2011.

SASSAROLI, A. Vírus da hepatite A: a presença e identificação dos genótipos circulantes nas águas de esgoto e de superfície da cidade de São Paulo, Brasil. 2002. 118f. Dissertação (Mestrado) - Instituto de Ciências Biomédicas, Universidade de São Paulo, São Paulo, 2002.

SHIRASAKI, N.; MATSUSHITA, T.; MATSUI, Y.; OSHIBA, A.; OHNO, K. Estimation of norovirus removal performance in a coagulation rapid sand filtration process by using recombinant norovirus VLPs. Water Res, [S, I.], v. 44, n. 5, p. 1307-1316, 2009.

SHUVAL, H. I. wastewater irrigation in developing countries: health effects and technical solutions. Bulletin Water and Sanitation Discussion Paper Series UNDP World Bank, [S, I.], n. 2, p. 75, 1990.

SHUVAL, H.; ADIN, A.; FAL, B.; RAWITZ, E.; YEKUTIEL, P. Wastewater irrigation in developing countries: health effects and technical solutions. Washington: World Bank Group, 1986.

TEMPLETON, M. R.; ANDREWS, R.C.; HOFMANN, R. Particle-associated viruses in water: impacts on disinfection processes. Crit Rev Environ Sci Technol, [S, I.], v. 38, p.137-164, 2008.

TSANG, K. W.; HO, P. L.; OOI, G. C.; YEE, W. K.; WANG, T.; CHANG-YEUNG, M..; LAM, W. K.; SETO, W. H.; YAM, L.Y.; CHEUNG, T. M.; WONG, P. C.; LAM, B.; IP, M.S.; CHAN, J.; YUEN, K.Y.; LAI, K. N. A cluster of cases of severe acute respiratory syndrome in Hong Kong. NEJM, [S, I.], v. 348, n. 20, p. 1977-1985.

VERBYLA, M. E.; MIHELCIC, J. R. A review of virus removal in wastewater treatment pond systems. Water Research, [S, I.], v. 71, n. 860, p. 107-124, 2015.

WAN, Y.; SHANG, J.; GRAHAM, R.; BARIC, R. S.; LI, F. Receptor recognition by novel coronavirus from Wuhan: an analysis based on decade-long structural studies of SARS. Journal Virology, [S, I.], v. 94, 2020.

WANG, X.; et al. Concentration and detection of SARS coronavirus in sewage from Xiao Tang Shan Hospital and the 309th Hospital of the Chinese People's Liberation Army. Water Science \&Technology, [S, I.], v. 52, n. 8, p. 213-221, 2005.

WANG, Y.; WU, X.; WANG, Y.; LI, B.; ZHOU, H.; YUAN, G.; FU, Y.; LUO, Y. Low stability of nucleocapsid protein in SARS virus†. Biochemistry, [S, I.], v. 43, n.34, p.11103-11108, 2004.

WHO issues consensus document on the epidemiology of SARS. Wkly Epidemiol Rec, [S, I.], v. 78, n. 43, p. 373-375.

WORLD HEALTH ORGANIZATIONS; UNITED NATIONS CHILDREN'S FUND. Water, sanitation, hygiene, and waste management for the COVID-19 virus 19/03/2020. Disponivel em: https://www.who.int/ publications-detail/water-sanitation-hygiene-and-waste-management-for-covid-19. Acesso em: 06 abr. 2020.

WIGGINTON, K. R.; KOHN, T. Virus disinfection mechanisms: the role of virus composition, structure, and function. Curr Opin Virol, [S. I.], v. 2, p. 84-89, 2012.

WIGGINTON, K. R.; YE, Y.; ELLENBERG, R. M. Emerging investigators series: the source and fate of pandemic viruses in the urban water cycle. the source and fate of pandemic viruses in the urban water cycle. Environmental Science: Water Research \& Technology, [S. I.], v. 1, n. 6, p. 735-746, 2015.

WOLFF, Manfred H.; SATTAR, Syed A.; ADEGBUNRIN, Olusola; TETRO, Jason. Environmental survival and microbicide inactivation of coronaviruses. Coronaviruses With Special Emphasis On First Insights Concerning Sars, [S. I.], p. 201-212, 2005.

WONG, K.; MUKHERJEE, B.; KAHLER, A. M.; ZEPP, R.; MOLINA, M. Influence of inorganic ions on aggregation and adsorption behaviors of human adenovirus. Environ Sci Technol, [S. I.] v. 46, n. 20, p. 11145-11153, 2012. 
WU, Fuqing; XIAO, Amy; ZHANG, Jianbo; GU, Xiaoqiong; LEE, Wei Lin; KAUFFMAN, Kathryn; HANAGE, William; MATUS, Mariana; GHAELI, Newsha; ENDO, Noriko. SARS-CoV-2 titers in wastewater are higher than expected from clinically confirmed cases. MedRxiv And Biorxiv, [S. I.], p. 1-14, 2020.

WU, Y.; GUO, C.; TANG, L.; HONG, Z.; ZHOU, J.; DONG, X.; YIN, H.; XIAO, Q.; TANG, Y.; QU, X.; KUANG, L.; FANG, X.; MISHRA, N.; LU, J.; SHAN, H.; JIANG, G.; HUANG, X. Prolonged presence of SARS-CoV-2 viral RNA in faecal samples. The Lancet Gastroenterology \& Hepatology, [S. I.], v. 5, n. 5, p. 434-435, 2020.

XAGORARAKI, I.; YIN, Z.; SVAMBAYEV, Z. Fate of viruses in water systems. J Environ Eng, [S. I.], v. 140, n. 7, p. 1-19.

XIAO, F.; et al. Evidence for gastrointestinal infection of SARS-CoV-2. Gastroenterology, [S. I.], v. 158, p. 1831-1833, 2020.

YE, Yinyin; ELLENBERG, Robert M.; GRAHAM, Katherine E.; WIGGINTON, Krista R. Survivability, partitioning, and recovery of enveloped viruses in untreated municipal wastewater. Environmental Science \& Technology, [S. I.], v. 50, n. 10, p. 5077-5085, 2016.

ZHANG, C. M.; et al. Elimination of viruses from domestic wastewater: requirements and technologies.

World Journal of Microbiology and Biotechnology, [S. I.], v. 32, n. 4, p. 1-9, 2016.

ZHANG, N.; GONG, Y.; MENG, F.; Bi Y.,YANG, P.; WANG, F. Virus shedding patterns in nasopharyngeal and fecal specimens of COVID-19 patients. MedRxiv, in press, [S. I.], 2020.

\section{Sobre os autores}

\section{Silvio Luiz de Sousa Rollemberg}

Engenheiro ambiental com experiência em projeto e operação de estações de tratamento de água e efluentes. Possui mestrado na UFC pelo Programa de Desenvolvimento e Meio Ambiente (Capes 5), doutorando em Saneamento Ambiental (UFC) no departamento de Engenharia hidráulica e ambiental (Capes 7). Já atuou em diversas empresas no segmento de saneamento ambiental. Atualmente, é consultor de P\&D na Fortech Ambiental e professor na Universidade de Fortaleza (Unifor) e Instituto Federal do Ceará (IFCE). Foi eleito diretor de saneamento ambiental da ABES-CE (mandato 2019-2021).

\section{Amanda Nascimento de Barros}

Engenheira ambiental pela Universidade Federal do Ceará, foi bolsista de Iniciação Científica do CNPq, por cerca de 4 anos, na área de tratamento de esgotos. Estagiou na Universidade de Western, London, Ontário, Canadá ocupou a função de analista ambiental na empresa ImplemenT Gestão; e atuou como bolsista DTI-C no Laboratório de saneamento da Universidade Federal do Ceará, com foco em lodo granular aeróbio e recuperação de subprodutos. Atualmente, é mestranda no programa de pósgraduação do departamento de Engenharia química da Universidade Federal do Ceará.

\section{João Pedro Machado de Lima}

Engenheiro ambiental pela Universidade Federal do Ceará. Especialização em andamento em Gestão e auditoria ambiental. Atua na empresa HL Soluções Ambientais, departamento técnico, com elaboração de estudos ambientais. Experiência enquanto estagiário na empresa Sanebrás - Projetos, Construções e Consultoria, no setor de projetos, auxiliando na elaboração de projetos de sistemas de abastecimento de água e sistemas de esgotamento sanitário, bem como na implantação da ISO 9001. Atuou, ainda, como voluntário no Laboratório de saneamento ambiental (Labosan) da UFC, de 2017 a 2019, em pesquisa focada no tratamento de efluentes por meio da técnica de lodo granular aeróbio, com autorias e coautorias em artigos publicados em âmbito nacional e internacional.

Recebido em: 27.04 .2020

Aceito em: 05.06.2020 